\title{
Chinese-English Translation from the Perspective of Chinese-English Compression -A Review of Functional Equivalence Theory
}

\author{
Jing Huang \\ East China University of Science and Technology, Shanghai, China \\ Email: 519117941@qq.com
}

How to cite this paper: Huang, J. (2021) Chinese-English Translation from the Perspective of Chinese-English CompressionA Review of Functional Equivalence Theory. Open Access Library Journal, 8: e7779. https://doi.org/10.4236/oalib.1107779

Received: July 21, 2021

Accepted: August 8, 2021

Published: August 11, 2021

Copyright $\odot 2021$ by author(s) and Open Access Library Inc.

This work is licensed under the Creative Commons Attribution International License (CC BY 4.0).

http://creativecommons.org/licenses/by/4.0/ (c) (i) Open Access

\begin{abstract}
The functional equivalence theory has aroused heated discussion in the field of translation. The theory of functional equivalence brings the reader's response into the translation process, provides a new standard paradigm for the evaluation of translation, and provides important guidance and reference for translation work. However, functional equivalence theory also has some shortcomings. Based on the compression characteristics of Chinese and English, this paper complements the functional equivalence theory from four aspects: the compression of the meaning boundary, the scope of the subject of the compression, the subjective meaning of the compression and the compression process of the compression.
\end{abstract}

\section{Subject Areas}

Chinese-English Translation

\section{Keywords}

Functional Equivalence, Compression, Chinese-English Translation

\section{Introduction}

Eugene Nida's functional equivalence theory has aroused heated discussion in the field of translation since it was put forward. This theory has changed the traditional translation theory which only pays attention to the performance of the Source text in the translation, and only pays attention to the equivalence between the translation and the Source text, and focuses on the readers instead. As Munday (2016) [1] pointed out that “... he (Nida) went a long way to producing a systematic analytical procedure for translators working with all kinds of texts 
and he factored into the translation equation the receivers of the TT and their cultural expectations", functional equivalence theory is of great significance in guiding the translation process and the evaluation of translation standards. But at the same time, functional equivalence theory also has some deficiencies, such as blurring the boundaries, attributing some differences in translation simply to equivalence, and failing to explain the specific reasons behind translation. This paper intends to make up for the lack of explanatory power of functional equivalence theory in translation by analyzing specific translation examples and proceeding from the compression characteristics of Chinese-English language.

\section{Theoretical Background}

\subsection{Functional Equivalence Theory}

Nida indicated that anything that can be expressed in one language can be expressed in another language; there is no such thing as an "advanced" language or a "backward" language that cannot be translated by finding translation equivalents between languages and cultures and reorganizing the Source form and semantic structure in an appropriate way. But not in the intralingual translation or interlingual translation, sure there are some differences between two different words that could not have absolute equivalence. In his book Toward a Science of Translating, Nida (1964) [2] from the perspective of social linguistics and language communication function, put forward the "dynamic equivalence" theory. He proposed that in translation, the translator is in a dynamic relationship, the relationship between the recipient of the target language and the information conveyed by the target language should be basically the same as that between the recipient of the source language and the source language. Nida's theory focuses on the equivalence of communicative effects in language communication rather than the formal equivalence prevailing at that time. He argued that the message must be tailored to the language needs and cultural expectations of the recipient, and "aimed at the complete naturalness of the expression". Nature is a key requirement of Nida. In fact, he defined the goal of dynamic equivalence as finding the closest natural counterpart to the source language information, and considered that the adjustment of grammar, vocabulary, and cultural references is a necessary condition for the realization of nature.

In From One Language to Another: Functional Equivalence in Bible Translation, Nida (1986) [3] changed the Source "dynamic equivalence" to "functional equivalence", that is, the translation requires not only the equivalent content of message, but, in so far as possible equivalent of the form. The word function regards translation as a form of communication, which focuses on the content and results of translation, so it is more reasonable than dynamic. Nida pointed out that translation is a communicative translation, without communication function, the translation would not be understood by the receiver, and would be unqualified and useless. Therefore, he put forward that translation should reflect the deep structure of functional equivalence rather than reflect the form of sur- 
face structure, and translation should make the readers of the translation text basically the same to the source readers understand and appreciate the source text. He pointed out that due to the differences of language and culture, in the form of the source text and the corresponding translation cannot be obtained, and can only be functionally equivalent different language expression. Even in different languages, there are some expressions that have the same or similar functions to each other, He proposed to save the source content, to reach functional equivalence of translation, must change the form of the language, and the degree of the change, depends on the cultural difference between different languages. To adjust the translation from form to content is the specific use of functional equivalence. Different expressing forms such as grammar, syntax and vocabulary do not affect the same function of the expression, the translator's task is to research the differences, figure out the best meaning and language style in the meaning and form closed system, make efforts to get closer to the Source language from form to the content.

In the Theory and Practice of Translation Nida (1969) [4] proposed that translation consists in reproducing in the receptor language the closest natural equivalent of the source language message, first in terms of meaning and second in terms of style. This definition includes the translation criterion "equivalence", which is the equivalence of meaning and language style. But before equivalence, there is the word natural, which means smooth and consistent. In Language and Culture: Context in Translating, Nida (2001) [5] proposed two levels of translation equivalence: the maximal equivalence and the minimal equivalence. The maximal equivalence refers to that the readers of a translated text should be able to understand and appreciate it essentially the same as the Source readers did. This level of translation, Nida believed, can never be achieved, especially when the cultural and aesthetic values of the two languages are greatly different. The minimal equivalence refers to that the readers of a translated text should be able to comprehend it to the point that they can conceive of how the Source readers of the text must have understood and appreciated it. This is a very basic requirement, anything less than this degree of equivalence should be unacceptable. According to Nida, the four basic requirements of a translation are: 1) making sense; 2) conveying the spirit and manner of the Source; 3) having a natural and easy form of expression; 4) producing a similar response.

Functional equivalence theory centers on the reader's response, that is, the reader's response to the information shown by the Source author after reading the translation. According to Nida, the service object of translation is the translation reader or the recipient of the translation language. The evaluation of the quality of the translation must be based on the reader's response to the translation, and at the same time it must be compared with the possible response of the Source reader to the Source text to see whether the two responses are consistent. The relationship between receptor and message should be absolutely the same as that which existed between the Source receptor and the message. To evaluate the 
quality of a translation, people have long been used to make a comparative study between the Source text and the target text, such as the expression forms of vocabulary, syntax, rhetoric and culture in the two languages. Nida noticed that the evaluation must be combined with the reaction of the readers of the translation. The reader's response is the sole criterion for judging translation quality, for this, translation must be natural and easy to understand; translators can even delete the parts that readers can't understand, such as metaphors. Moreover, Nida believed that translators in dealing with the words and sentences reflect the national culture, if there is a cultural default which requires the information supplement in the translation to translate the unspoken implicit elements of the Source text into words.

Nida's functional equivalence theory proposes a new criterion for translation evaluation: the success of translation depends on whether the readers of translation achieve the greatest degree of the Source readers' reaction to the Source text. Besides, Functional equivalence theory changes the traditional view that translation is a single process from the Source text to the translator and then to the translation. Instead, translation readers and their understanding and reaction to the translation are also included in the translation process. At the same time, functional equivalence theory also has some limitations. For example, the translation criterion is that the readers of the translated text meet the same response as the readers of the Source text. However, due to the limitations of history and culture, the judgment standard of the same response is subjective and difficult to achieve. At the same time, it is too subjective to attribute some translation processing that is different from the Source text to serving the readers' understanding, and not enough to explain the reasons behind the translation processing selection.

\subsection{Compression Features of Chinese-English}

Wang Jianguo (2019) [6] believed that there are differences in the modes of thinking, aesthetics, and pragmatics between the Chinese and English languages. These differences are full of significance to guide and explain the process of translation. Wang Jianguo pointed out that Chinese morphology, syntax and chapters have little overlap, and the boundaries between language structures are not clear. This shows that the ways of word formation and sentence construction in Chinese reflect the vague individual consciousness of Chinese native speakers. As the whole cannot be separated from the individual, the individual constitutes the whole, and the individual consciousness and the whole consciousness have the inherent unity, so the whole consciousness of Chinese native speakers is also relatively vague. In terms of morphology, the categorization of word formation in Chinese is characterized by fuzziness, which directly leads to the unclear boundary of grammatical structure units in Chinese. While the derivational word-formation in English has a lot of affix marks and the functions of word classes are clearer. Syntactically, there are many run-on sentences in Chinese, which form parallel structures without priority or priority, and the structure hierarchy between sen- 
tences is ambiguous. The English syntax structure is clear. In terms of discourse, Chinese texts are mostly constructed with topic chains, and the boundaries between topic chains are also ambiguous. In addition to the differences between individual consciousness and overall consciousness, there are also differences between subject consciousness and object consciousness in the way of thinking between Chinese and English. Chinese native speakers have strong subjective consciousness, and the whole event expressed is subjective and conjectural. Within a single event, the representation of events emphasizes the participation of subjective consciousness. In terms of the relations between events, they are more connected from the subjective perspective. To the contrary, native English speakers have a stronger sense of object, and they tend to narrate events from an objective perspective, emphasizing the objective existence of things per se. Wang (2016) [7] also pointed out that native English speakers have a stronger sense of time and space. In English, the sentence structure with distinct priorities shows stereoscopic sense, while the temporal markers in language show a strong sense of time limit. The differences between Chinese and English modes of thinking are consistent with the differences in aesthetics. English has a precise, concise and stereoscopic aesthetic, while Chinese has a redundant, concise and plane aesthetic. Wang Jianguo (2014) [8] proposed that Chinese is a kinetic energy oriented language. In order to obtain greater psychological potential energy, Chinese tends to use a large number of content words to increase the psychological quality of discourse. The kinetic energy orientation of Chinese aesthetics is reflected in the extensive use of modifiers, emphasis and even exaggeration of details, extensive use of reduplicated words or repeated structures, and extensive use of verbs. English is a potential energy oriented language, which tends to gain elevation by reducing its load.

The differences between Chinese and English in the modes of thinking, aesthetics and pragmatics can be summarized to show that English is more compressed. Based on the fact that English is more compressed than Chinese, Wang Jianguo proposed a compression strategy to guide Chinese-English translation. Wang Jianguo pointed out that compression does not refer to the form of compression, but to the content of the compression, is to figure out the focus, and form a kind of boundary compression around the focus, which is to make the focus much more clear and make accurate boundary compression. That is to say, the compression strategy refers to enhance the exclusivity of the content, improve the accuracy and reduce the imagination of the reader. However, due to the different ways of compression, the translation may be more concise than the Source in form, and may also be expanded in part.

\section{Analysis of Translation Examples}

\subsection{The Compression of the Meaning Boundary}

Example (1)

Source text: 他活着的时候, 人们都叫他阿 Quei, 死了以后, 便没有一个人 
再叫阿 Quei 了, 哪里还会有 “著之竹帛” 的事。( The True Story of Ah Q)

Yang Xianyi's translation: During his lifetime everybody called him Ah Gui, but after his death not a soul mentioned Ah Gui again; for he was obviously not one of those whose name is "preserved on bamboo tablets and silk". (Note: a phrase used before paper was invented when bamboo and silk served as writing material in china.)

In On the Translation of Lu Xun's Novel The True Story of Ah Q by Yang Xianyi and Gladys Yang from the Perspective of Nida's Functional Equivalence Theory, taking this sentence as an example, Chen Weijia [9] tries to analyze Yang xianyi's translation. The author points out that Yang's translation explains the word “著之竹帛(the bamboo and silk)”, a word that carries the unique cultural connotation of China, by adding annotations. This translation strategy is an adopting of Nida's functional equivalence theory to enable English readers to understand the role of bamboo and silk in ancient China. However, it is not enough to explain the deep reasons behind the use of annotation by the translator only to explain the annotation by functional equivalence theory. Wang jianguo pointed out that the adding information translation method actually plays the function of compression, that is, to clarify the boundaries, make the boundaries clearer, and make related concepts more exclusive. Here Yang Xianyi took one of the adding information translation methods-the annotated translation method.

The use of bamboo and silk as writing materials is a unique cultural phenomenon in the context of Chinese culture; it has the unique history of China. However, separated from the historical and cultural background of China and placed in the English context, English readers, based on their inherent cognition, have difficulty in connecting bamboo and silk with writing, and thus would tend to misunderstand the cultural concept conveyed by this word. By adding an explanation of the word, Yang enabled the English readers to understand the writing function of bamboo and silk in ancient China, which limited the English readers' understanding of bamboo and silk, preventing them from having the understanding that is different from the Source meaning. That is, the annotated translation method Yang used in this translation is aims to limit the understanding boundary of English readers.

Example (2)

Source text: “其实呢，去年我们将他们的灶都拆掉了，总算已经出了一口 恶气。” (Divorce)

Yang Xianyi's translation: "Well ... As a matter of fact, since we pulled down their kitchen range last year we've had our revenge more or less."

Julia Lovell's translation: "Well, I'll be ... Anyway, we taught them a lesson or two when we smashed their stove up last year."

Similar to example 1, in this example from Translation Study of Language Deviation under the Guidance of Functional Equivalence Theory-A Case Study of Lu Xun's Novel Divorce by Ye and Yu [10], the act of pulling down the kitchen range has a unique cultural significance. In the traditional concept of China, the hearth is not only an ordinary kitchen appliance, but also the guarantee of a 
family's diet. Hearth is in representation of the basis of family livelihood, has important meaning. Pulling down the hearth/smashing the strove of the other's home, it is to destroy the basis that the other family survive, means great of anger catharsis. Therefore, pulling down the hearth not only refers to the behavior of removing the stove, but also reflects the degree of anger of the actors, is a retaliatory behavior. In Lovell's translation, through clever footnotes, the imagination space of the English readers is compressed, and the English readers can appreciate the cultural meaning behind the text that Chinese readers can understand when they read the Source.

Example (3)

Source text: 几年来的文治武力, 在我早如幼小时候所读过的 “子曰诗云” 一般, 背不上半句了。独有这一件小事, 却总是浮在我眼前…… ( A Little Thing)

Yang Xianyi's translation: The politics and the fighting of those years have slipped my mind as completely as the classics I read as a child. Yet this small incident keeps coming back to me...

Li Ming's translation: The military and political affairs of all those years have escaped me as completely as the classics I had read as a child. Only this incident keeps up before my eyes...

In this example from A Comparative Study of Two English Translations of A Little Thing under the Theory of Functional Equivalence, the author Li Huizi [11]'s explanation of functional equivalence in syntactic relation is insufficient. Chinese run-on sentences have the beauty of smooth and flowing, but the relation between sentences is rather ambiguous, with a special way of cohesion to form coherence. Wang Jianguo (2017) [12] pointed out that since there is no fixed tense mark in Chinese, its mark is often reflected by vocabulary. In the example sentences, “几年来(all those years)” has reflected the mark of the tense, and in the English examples the tense of the passive word is manifested. In the Source Chinese sentence, the relationship between the two clauses is not obvious due to the vague boundary consciousness of Chinese, and the two clauses lack a single cohesive word, which only constitutes parataxis. However, in English, English sentences are often clearly defined, and the words that mark the relationship between sentences cannot be omitted. In the translation, by adding the adjunctive word "yet", Yang Xianyi highlighted the adjunctive relationship implied by the two clauses in the Source sentence and defines the boundary of the relationship between sentences. To strengthen the sense of boundary, reconstruct or strengthen the logical relation between sentences, all of these are to compress the boundary of sentences to make up for the pragmatic difference between Chinese and English.

\subsection{The Compression of Subject Range}

Example (4)

Source text: 倘要我寻出这些事的影响来说, 便只是增长了我的坏脾气, 一 一老实说, 便是教我一天比一天的看不起人。(A Little Thing) 
Yang Xianyi's translation: If asked to define their influence on me, I can only say they made my bad temper worse. Frankly speaking, they taught me to take a poorer view of people every day.

Li Ming's translation: If asked to decide on their impact on me, I can only say that they have sharpened my ill-temper-or to be frank, they have caused me to become more and more disdainful.

In example 4, from the perspective of functional equivalence, the author mainly focused on the translation differences of the phrase “看不起人(looking down on people)" in the two translations. However, Li Huizi only interprets the differences in translation as a way to avoid misunderstandings, but fails to explain why misunderstandings should be avoided with the theory of functional equivalence. In fact, this translation process is also about compression.

Yang Xianyi translated the phrase into "take a poorer view of people", explained the meaning of the Source sentence, to avoid the misunderstanding, and compressed the reader's imagination boundary. Therefore, the position and attitude of Luxun are accurately expressed; the English reader could have a better understanding of the novel's theme. In Li Ming's translation version, the translator used the word disdainful. The word disdainful means showing that you do not respect sb., because you think that they are not important or good enough, contains the meaning both of "do not respect" and "not good enough" in one word. This also demonstrates the high compressibility of English words. At the same time, due to the structure of run-on sentences in Chinese, the boundaries of clauses are ambiguous and the relationship between sentences is rather vague. For example, the sentence “(便是教我一天比一天的看不起人) is to teach me to look down on people day by day" lacks a clear subject. But in Chinese, even with subject absence, because of the unique construction of Chinese sentences, the meaning of the whole sentence is still understandable. Because of its clear sense of boundaries, English requires a clear subject in a sentence. Therefore, in the translation, Yang Xianyi and Li Ming both chose to restore the missing subject by adding the subject "they".

Example (5)

Source text: 我想, 我眼见你慢慢倒地, 怎么会摔坏呢, 装腔作势罢了, 这 真是可憎恶。车夫多事, 也正是自讨苦吃, 现在你自己想法去。( $A$ Little Thing)

Yang Xianyi's translation: I thought: I saw how slowly you fell, how could you be hurt? Putting on an act like this is simply disgusting. The rickshaw man asked for trouble, and now he's got it. He'll have to find his own way out.

Li Ming's translation: I have seen you fall down slowly and how could you hurt yourself? I thought. You are just pretending. How disgusting of you! And the rickshaw man had been asking for trouble and now he really had it! And now he had to find his way out.

Similar to example 4, in the sentence “这真是可憎恶(this is disgusting)", the subject of "this" is ambiguous. It may refer to your falling, or it may refer to the fact that I saw you fall. The author Li Huizi ignores this point when analyzing the two translations and only analyzes the translation from the perspective of 
tone, and only the equivalence of the translation and the Source in tone is considered. In the translation of this sentence, both Yang Xianyi and Li Ming, consciously or unconsciously, choose to deal with the ambiguity of the subject in the Source text. Both the two translators chose to reclassify the long sentences of the Source text, and split them into several clauses based on the meaning, so as to highlight the unclear subjects in the Source text.

\subsection{The Compression of Subjective Sense}

Example (6)

Source text: “又有些胜利者, 当克服了一切之后, 看见死的死了, 降的降 了, “臣诚惶诚恐死罪死罪”, 他于是没有了敌人, 没有对手, 没有了朋友, 只有自己在上, 一个, 孤零零, 凄凉, 寂寞, 便反而感到了胜利的悲哀了。” ( The True Story of Ah Q)

Yang Xianyi's translation: “there are other victors who, having carried all before them, with the enemy slain or surrendered, utterly cowed, realize that now no foe, no rival, no friend is left-none but themselves supreme, lonely lost and forlorn. Then find their triumph a tragedy."

Chen Weijia believes that Yang Xianyi's translation in example 5 maintains functional equivalence in meaning and style with the Source text. The author holds that the translation is graceful and smooth, which makes the text pleasant to read and gives people a kind of phonological beauty. However, as Wang Jianguo pointed out, the musical beauty of Chinese language mainly depends on the rhythmic beauty of balance and symmetrical structure, which is characterized by a sense of plane. As a kinetic aesthetic-oriented language, Chinese tends to use a large number of word structures with repeated meanings to increase the psychological potential and gain a stronger aesthetic feeling. In the Source text, words such as “死的死(dead are dead)”, “降的降了(surrenderors surrendered)” and “诚惶诚恐死罪死罪(with reverence and awe)” constitute semantic repetition, which also reflects the vagueness of word class in Chinese. “没有了敌人、没 有对手、没有朋友(No enemies, no rivals, no friends)” is a structural repetition, and “孤零零、凄凉、寂寞(Solitude, desolation, and loneliness)” represent repetition of sense. These expressions are the embodiment of Chinese kinetic energy oriented aesthetics. As a potential energy oriented aesthetic language, English does not need these types of expressions, and even tries to avoid using repetitive expressions. Therefore, in the translation, Yang Xianyi reorganizes the sentence structure of the Source text to clarify the focus of the description-the enemy. And the decorations- "slain or surrendered, utterly cowed" are all around this focus, thus the center is more prominent, the main and secondary status is more clear. Because of the strong subjective consciousness of Chinese native speakers, there are often a lot of subjective expressions in Chinese. Wang Jianguo figured out that the Chinese style of writing likes to start from the perspective of a person, who can be a clearly identifiable entity, a vague group, or even an elusive person or group. As a result, a large number of subjectively colored words will ap- 
pear in Chinese discourse, producing a large number of subjective meanings. The sentence “臣诚惶诚恐死罪死(I fear the death penalty)” in the Source Chinese text is completely a subjective expression.

For such subjective expression that is completely a characteristic of Chinese, Yang Xianyi adopted deletion in his translation. Deleting the expression of high subjective meaning in the Source text is also a common compression strategy in the Chinese-English translation.

Example (7)

Source text: “他意思之间, 似乎觉得人生天地间大约本来有时也未免要杀 头的。” ( The True Story of $A h Q$ )

Yang Xianyi's translation: "It seemed to him that in this world probably it was the fate of everybody at some time to have his head cut off."

Lyell's translation: "As his mind flickered on and off, Ah Q concluded that in this old world of ours there must be times when a man is supposed to get hauled away and have his head chopped off".

The Source text of example 7 is also full of Chinese language features. The whole sentence of the Source text is a subjective expression, which is a completely speculative event. The words “意思之间(between his words)” and “觉得 (thought)" in the sentence constitute a complete repetition of the meaning, while the words such as “似乎(seemingly)”, “大约(about)”, “有时(sometimes)” highlight the obscurity of the Chinese language. Zhang Qianqian [13] thinks that both Yang's translation and Lyell's translation adopt the method of translating only two or three function words, instead of blindly pursuing formal equivalence, they basically retain the style of the Source text. In fact, this is a result of the different usage characteristics of content words in Chinese and English, which cannot be explained from the perspective of functional equivalence. In addition, the author of the Source text believes that Lyell's translating “似乎觉 得” into “conclude” seems inappropriate, because “似乎觉得” is a certain tone, and "conclude" is uncertain tone. Taking the compression features of English into consideration, Lyell's translation demonstrates the compression of the subjective meaning of the Source information.

\subsection{The Compression of Process}

Example (8)

Source text: “窃书不能算偷…...” (Kong Yiji)

Yang Xianyi's translation: "Taking books can't be counted as stealing ..."

Lyell's translation: "The purloining of volumes, good sir, cannot be counted as theft."

In example 8, from the perspective of functional equivalence, Chen Weijia, focuses on the formal distinction between the two words “窃(purloin)” and “偷 (steal)" in the Source text, and believes that Lyell's translation achieved functional equivalence by translating “窃” into "purlion" and “偷” into "steal". Comparatively, Yang Xianyi translated “窃” as “take”, which was not formal enough and did not achieve functional equivalence. This explanation can only explain 
the difference between the two translators in terms of diction, but cannot explain the change of part of speech made by the translation author when compared with the words in the Source text. Wang jianguo put forward that Chinese is a process-oriented language, and the process and results of Chinese have no clear boundaries, are continuous, that is, are unbounded. The process and the result of English are intermittent, that is, are bounded.

From the verb “窃/偷” in the Source text to the noun "purloining” and “theft” in the translation, the transformation of part of speech reflects the compression of the process meaning of describing events in the Source Chinese text.

Example (9)

Source text: “就是到庞庄去走一遭。” (Divorce)

Yang Xianyi's translation: "We're making a trip to Pang Village."

Lovell's translation: "To Pangzhuang."

In example 9, the “走一遭” in the Source Chinese text contains the whole process of “走(go)", which fully reflects the characteristics of Chinese process orientation. Ye Yufei and Yu Xiao only analyzes from the indicated entertainment of the word "trip" used in Yang Xianyi's translation, and thinks that this translation is easy to mislead readers. Yang Xianyi translated “走一遭” into “make a trip", which still reflects the process orientation characteristics of Chinese. While in Lovell's translation, "to Pangzhuang" not only simply highlights the destination, but also advances the meaning of the Source text and directly points out the results of this process, embodies the result orientation feature of English.

\section{Conclusion}

This paper studies some works that take functional equivalence theory to analyze translation examples, and finds that functional equivalence theory can indeed explain some translation choices and has certain guiding significance for translation. However, the explanatory power of the theory of functional equivalence is relatively insufficient, which fails to make a deep understanding of the reasons behind the translator's translation choices. Based on the compression characteristics of Chinese-English, this paper complements the application of functional equivalence theory in translation cases from four aspects: the compression of meaning boundary, the compression of subject range, the compression of subjective meaning and the compression of process, and explains the translation process more sufficiently. On the other hand, this paper focuses on several certain cases merely, which is relatively unspecific and in-depth. Therefore, more corpus-based study on this topic is still in need.

\section{Conflicts of Interest}

The author declares no conflicts of interest regarding the publication of this paper.

\section{References}

[1] Munday, J. (2016) Introducing Translation Studies Theories and Applications. 
Routledge, London. https://doi.org/10.4324/9781315691862

[2] Nida, E.A. (1964) Toward a Science of Translating. E. J. Brill, Leiden. https://doi.org/10.1163/9789004495746

[3] De Waard, J. and Nida, E.A. (1986) From One Language to Another: Functional Equivalence in Bible Translation. Thomas Nelson Inc., Edinburgh.

[4] Nida, E.A. and Taber, C.R. (1969) The Theory and Practice of Translation. E. J. Brill, Leiden.

[5] Nida, E.A. (2001) Language and Culture: Context in Translating. Shanghai Foreign Language Education Press, Shanghai.

[6] 王建国. 汉英翻译学: 基础理论与实践 [M]. 北京: 中译出版社, 2019.

[7] 王建国. 汉英翻译中顺应因素的层次研究 [M]//王建国. 语用人生一一何自然教 授八十华诞庆贺文集. 北京: 高等教育出版社, 2016: 275-283.

[8] 王建国, 何自然.重过程,还是重结果?一一译者的母语对英译文本的影响 [J]. 上海 翻译, 2014 (2): 7-12.

[9] 陈维嘉. 从奈达的功能对等理论看杨宪益、戴乃迭翻译的鲁迅小说《阿 $\mathrm{Q}$ 正传》 [J]. 语文学刊 (外语教育与教学), 2009(3): 79-81.

[10] 叶雨飞, 余笑. 功能对等理论指导下语言偏离的翻译研究一一以鲁迅小说《离婚》 为例 [J]. 戏剧之家, 2018(31): 202-203+215.

[11] 李慧姿. 功能对等理论下《一件小事》两个英译本的对比研究[J]. 邢台学院学报, 2011, 26(4): 83-85.

[12] 吴碧宇, 王建国. 汉英审美观差异及其语言表现[J]. 华东理工大学学报(社会科 学版), 2017, 32(2): 98-106+116.

[13] 张茜茜. 从奈达的功能对等角度评析 《呐喊》的两个英译本 $[\mathrm{J}]$. 湖北科技学院学 报, 2016,36(2): 137-138+150. 